

\title{
Knowledge, Attitude and Uptake of Pap Smear among Female Healthcare Professionals in a Nigerian Teaching Hospital Olarinoye $\mathrm{AO}^{1,2}$, Shiru $\mathrm{MM}^{1}$, Ubom $\mathrm{AE}^{* 3}$, Olabinjo $\mathrm{AO}^{1}$, Abdul $\mathrm{IF}^{1,2}$, Ijarotimi $\mathrm{AO}^{3,4}$, Nyeche $\mathrm{S}^{5,6}$, Oriji $\mathrm{PC}^{7}$, Amadi $\mathrm{L}^{8}$, Ikimalo JI ${ }^{5,6}$
}

1Department of Obstetrics and Gynaecology, University of Ilorin Teaching Hospital, Kwara State, Nigeria ${ }^{2}$ Department of Obstetrics and Gynaecology, University of Ilorin, Kwara State, Nigeria

${ }^{3}$ Department of Obstetrics, Gynaecology and Perinatology, Obafemi Awolowo University Teaching Hospitals Complex, Ile-Ife, Osun State, Nigeria

4Department of Obstetrics, Gynaecology, and Perinatology, Faculty of Clinical Sciences, College of Health Sciences, Obafemi Awolowo University, Ile-Ife, Osun State, Nigeria

${ }^{5}$ Department of Obstetrics and Gynaecology, University of Port Harcourt Teaching Hospital, Port Harcourt, Rivers State, Nigeria

${ }^{6}$ Department of Obstetrics and Gynaecology, University of Port Harcourt, Port Harcourt, Rivers State, Nigeria 7Department of Obstetrics and Gynaecology, Federal Medical Centre, Yenegoa, Bayelsa State, Nigeria 8South Shore Women's and Children's Hospital, Victoria Island, Lagos State, Nigeria

*Correspondence: Dr AE Ubom, Department of Obstetrics, Gynaecology and Perinatology, Obafemi Awolowo University Teaching Hospitals Complex, Ile-Ife, Osun State, Nigeria. World Association of Trainees in Obstetrics and Gynaecology (WATOG). E-mail: bedom2001@yahoo.com, akaninyeneubom@oauthc.com; ORCID - https://orcid.org/0000-0002-7543-0510.

\begin{abstract}
Background: Despite the high prevalence of cervical cancer (CC) in Nigeria, the uptake of screening services, including Pap smear, remains poor, even amongst healthcare providers.

Objective: To assess Pap smear knowledge, attitude, and uptake among female healthcare professionals (FHPs).

Methods: A cross-sectional descriptive study was conducted at the University of Ilorin Teaching Hospital (UITH), Kwara State, Nigeria, using a self-administered questionnaire.

Results: A majority $(343,98.6 \%)$ of the FHPs knew Pap smear. Five (26.3\%) medical laboratory scientists did not know what a Pap smear was. All the nurses, doctors, pharmacists, physiotherapists and medical social workers knew Pap smear. Only a fifth $(71 ; 20.4 \%)$ of the FHPs had ever done a Pap smear. The most common reason cited for not having done a Pap smear was lack of time $(109 ; 31.3 \%)$. There was a relationship between age and uptake of Pap smear $(p=$ 0.024). Only 188 (54\%) of the FHPs had ever recommended Pap smear to other women.

Conclusion: Despite the high level of knowledge of Pap smear amongst FHPs in Nigeria, attitude and uptake remain poor. There is a need for further training and education of FHPs on the benefits of CC screening to increase their uptake and improve their effectiveness in promoting positive attitudes towards CC screening and prevention in the general population.
\end{abstract}

Keywords: Cervical cancer, Gynaecological malignancy, Nigeria, Papanicolaou smear, Prevention, Screening. 


\section{Introduction}

Cervical cancer (CC) is the most common gynaecological malignancy in the developing world, and the second most common cancer in women worldwide, after breast cancer.[1] Globally, over 530,000 new cases and about 270,000 related deaths are recorded annually, making CC the fourth most lethal cancer in women worldwide. [2] More than $80 \%$ of CC deaths occur in low- and middle-income countries, with sub-Saharan Africa (SSA) accounting for $22 \%$ of the global burden of CC. [3,4] In Nigeria, 53.3 million women are at risk of CC, with a national prevalence rate of $250 / 100,000$, a yearly incidence of 9,922 new cases, and 8,030 deaths. [5,6] This ranks Nigeria fifth in CC mortality, after India, China, Brazil, and Bangladesh.[7]

Infection with the Human Papilloma Virus (HPV) is the aetiological factor in over $99 \%$ of CCs. ${ }^{[8-10]}$ In SSA, the prevalence of HPV infection in women averages $24 \%$, which is double the global prevalence. [11] Given the association between HPV infection and CC, a very effective primary preventive measure is the vaccination of pre-adolescent girls against oncogenic strains of HPV before their sexual debut. [5] However, the Human Papilloma Virus vaccine is yet to be included in the National Immunization Schedule in Nigeria. Therefore, it is not freely available to all pre-adolescents in the country. The uptake of the HPV vaccine in Nigeria is currently hampered by its cost and poor knowledge.[12]

The Papanicolaou (Pap) smear, a secondary preventive measure that screens for preinvasive cervical lesions, is the most cost-effective strategy for early detection of $\mathrm{CC}$ and the best alternative to $\mathrm{HPV}$ vaccination. It has reduced the incidence and mortality from CC in developed countries by over $70 \% .{ }^{[13]}$ However, the uptake of Pap smear in SSA is still poor, with coverage varying between less than $10 \%$ and $50 \%$, due to various reasons such as poverty, illiteracy and nonavailability or sparse distribution of screening centres. ${ }^{[1,14]}$ These factors are also responsible for the inter-country differentials in uptake in the region. While uptake rates of between 3\%-23.8\% have been reported in Nigeria, Akokowebe et al. documented a Pap smear uptake rate of $35.4 \%$ in South Africa. [15-17]

Female healthcare professionals (FHPs) play critical roles in creating awareness and promoting the uptake of Pap smears in the general population.[18] Their knowledge and acceptance of Pap smear influence their willingness/readiness to recommend the same to other women. ${ }^{[14]}$ More so, FHPs are also at risk of CC. Therefore, it is crucial to assess their knowledge, attitude and uptake of Pap smear. Therefore, this study evaluated Pap smear's knowledge, attitude, and uptake amongst FHPs at the University of Ilorin Teaching Hospital (UITH), Kwara State, Nigeria.

\section{Methods}

Study design: This cross-sectional, descriptive study was conducted between 18 July 2020 and 23 December 2020. As used in this study, female healthcare professionals refer to female medical doctors, nurses, pharmacists, medical laboratory scientists, physiotherapists, and medical social workers. ${ }^{[15]}$ The questionnaire was based on the CC screening guidelines of the Society of Obstetrics and Gynaecology of Nigeria (SOGON), which recommend screening for women between the ages of 25 and 65 years, at three-yearly intervals. ${ }^{[19]}$

Study location: The study was conducted at the UITH, Kwara State, North-Central Nigeria.

Sample size determination: The minimal sample size was calculated using the formula for calculating single proportion: $\mathrm{n}=\mathrm{z}^{2} \times \mathrm{p} \times(1-\mathrm{p}) / \mathrm{e}^{2}$, 
where $\mathrm{n}=$ sample size, $\mathrm{z}=$ standard normal variate (which is 1.96 for a confidence level of $95 \%), p=69.8 \%(0.689)$, which is the proportion of female health workers aware of Pap smear from a previous study, ${ }^{[15]} \mathrm{e}=$ margin of error, which is 0.05 at $95 \%$ confidence level.

A minimum sample size of 324 was calculated using that formula. Allowing for a $10 \%$ rate of non-response, the estimated minimum sample size was 356.

Inclusion and exclusion criteria: All CC-näive FHPs in UITH were included in the study, while all FHPs in UITH, with previous or current CC, were excluded.

Ethical considerations: Ethical approval for the study was obtained from the Ethics Committee of the University of Ilorin Teaching Hospital, Kwara State, Nigeria (ERCPAN/2020/07/0031). Informed consent was also obtained from each of the study participants before they completed the study questionnaire.

Sampling method: The UITH has 1,016 FHPs, comprising 687 nurses, 159 medical doctors, 72 pharmacists, 57 medical laboratory scientists, 23 physiotherapists, and 18 medical social workers. A multistage sampling method was used to select the study participants. In the first stage, the different groups of FHPs were identified, as highlighted above. In the second stage, the population of each group of FHPs was obtained, and sample sizes were proportionately allocated based on the population of each group. In the final stage, the FHPs were randomly selected from each professional group, based on each group's allocated sample size, until the calculated sample size of 356 was obtained. The study respondents comprised 241 nurses, 56 medical doctors, 25 pharmacists, 20 medical laboratory scientists, eight physiotherapists, and six medical social workers, approximately a third of the population of each professional group.

Study instrument: The data collection tool was a purpose-designed, self-administered questionnaire, which gathered information on sociodemographic characteristics, knowledge of CC, risk factors, symptoms, Pap smear, and uptake of Pap smear.

Data analysis: The data obtained were analysed using the Statistical Package for Social Sciences (SPSS), version 24. Calculated frequencies and percentages were presented in tables and figures. Associations between categorical independent and outcome variables were assessed where applicable, using the Chi-Square test with a level of significance set at $<0.05$.

\section{Results}

Of the 356 questionnaires distributed, 348 were returned filled, giving a response rate of $97.8 \%$.

Sociodemographic characteristics of respondents

The mean age of the respondents was 34 years. Most of the respondents were nurses $(239 ; 68.7 \%)$, married $(239 ; 68.7 \%)$, and in the third decade of life $(148 ; 42.5 \%)$. All the respondents had tertiary level education. These sociodemographic characteristics are shown in Table I. 
Table I: Sociodemographic characteristics of FHPs

\begin{tabular}{lll}
\hline Characteristics & $\begin{array}{l}\text { Frequency } \\
\boldsymbol{n}=348\end{array}$ & Percentage \\
\hline Age (years) & 148 & \\
$20-29$ & 102 & 42.5 \\
$30-39$ & 61 & 29.3 \\
$40-49$ & 37 & 17.5 \\
$\geq 50$ & & 10.6 \\
Marital status & 239 & \\
Married & 103 & 68.7 \\
Single & 4 & 29.6 \\
Divorced & 2 & 1.1 \\
Widowed & & 0.6 \\
Parity & 182 & \\
$0-2$ & 155 & 52.3 \\
$3-4$ & 11 & 44.5 \\
$\geq 5$ & & 3.2 \\
Designation & 239 & \\
Nurse & 55 & 68.7 \\
Medical Doctor & 23 & 15.8 \\
Pharmacist & 19 & 6.6 \\
Medical Laboratory Scientist & 8 & 5.5 \\
Physiotherapist & 4 & 2.3 \\
Medical Social Worker & & 1.1 \\
\hline
\end{tabular}

Knowledge of cervical cancer

A majority of the respondents had heard of CC $(314 ; 90.2 \%)$, and more than one-half of them had participated in caring for patients with CC (199; $57.2 \%)$. The most common risk factor for CC, reported by the respondents, was multiple sexual partners (337; 96.8\%), while the most commonly reported symptom was bleeding per vaginam (340; 97.7\%). Pap smear was identified as the most common CC screening method (343; 98.6\%). Less than two-thirds knew that colposcopy (199; $57.2 \%)$ and visual inspection with acetic acid (VIA) (188; 54.0\%) were also CC screening methods, as depicted in Table II. Overall, only $139(39.9 \%)$ of the FHPs had good knowledge of the risk factors, symptoms, and screening methods for CC.

Knowledge, attitude and uptake of Pap smear Most of the respondents (343; 98.6\%) had heard of Pap smear, and most of them (231; 66.4\%) heard of it from formal lectures during their undergraduate training. There was no statistically significant association between profession/designation and knowledge of Pap smear $(p=0.327)$. More than three-quarters $(268$; $77.0 \%$ ) of the FHPs knew that Pap smear was used to screen for $\mathrm{CC}$, but less than a third of them $(105 ; 30.2 \%)$ knew that the screening should commence from 25 years of age. 
Table II: Knowledge of Cervical Cancer amongst FHPs

\begin{tabular}{lll}
\hline Characteristics & Frequency, $\boldsymbol{n}=\mathbf{3 4 8}$ & Percentage \\
\hline What are the risk factors for cervical cancer? & & \\
Multiple sexual partners & 337 & 96.8 \\
HPV infection & 326 & 93.7 \\
Immunosuppression & 299 & 85.9 \\
Early coitarche & 284 & 81.6 \\
Smoking & 250 & 71.8 \\
Multiparity & 243 & 69.8 \\
What are the symptoms of cervical cancer? & & \\
Bleeding per vaginam & 340 & 97.7 \\
Post-coital bleeding & 336 & 96.6 \\
Foul-smelling vaginal discharge & 326 & 93.7 \\
Post-menopausal bleeding & 325 & 93.4 \\
Weight loss & 307 & 88.2 \\
What are the screening methods for cervical cancer? & & \\
Pap smear & 343 & 98.6 \\
HPV DNA testing & 246 & 70.7 \\
Colposcopy & 199 & 57.2 \\
Visual inspection with acetic acid (VIA) & 188 & 54.0 \\
\hline
\end{tabular}

Slightly more than one-half (180; 51.7\%) of the respondents reported knowing that Pap smear was recommended every three years, and most of them $(284 ; 81.6 \%)$ were aware a positive Pap smear result did not mean a woman had CC. Overall, only 105 (30.2\%) of the FHPs had good knowledge of the indication, age to start, and interval of Pap smear screening.

Only a fifth $(71 ; 20.4 \%)$ of the FHPs had ever done a Pap smear. There was no significant association between profession/designation and uptake of Pap smear $(p=0.327)$. Most FHPs who had never done a Pap smear gave no reason $(109 ; 31.3 \%)$. Of those who gave reasons, the most common reason was lack of time to go for the test (83; $23.9 \%)$. Almost a fifth $(59 ; 17 \%)$ believed they were not at risk of CC. Twelve respondents $(3.4 \%)$ did not know the test was available in their hospital. Other reasons are as shown in Table III. The knowledge of cervical cancer and Pap smear was not significantly associated with uptake of Pap smear ( $\mathrm{p}=0.188$ and 0.254 , respectively). Only a little over one-half $(188 ; 54.0 \%)$ of the respondents had ever recommended Pap smear to other women. There was a statistically significant relationship between profession and recommendation of Pap smear by the FHPs $(\mathrm{p}=$ $0.001)$. More than one-half of the medical doctors (33; 60.0\%), and nurses (139; 58.2\%), and one-half of the physiotherapists $(4 ; 50.0 \%)$, had recommended Pap smear to other women. In comparison, less than one-half of pharmacists (10; $43.5 \%)$, one-fourth of medical social workers (1; $25.0 \%)$, and only five per cent of medical laboratory scientists $(1 ; 5.3 \%)$ had recommended Pap smear to other women. These findings are shown in Figure 1. 
Table IIIa: Knowledge of Pap smear amongst FHPs

\begin{tabular}{lll}
\hline Characteristics & $\begin{array}{l}\text { Frequency } \\
n=348\end{array}$ & Percentage \\
\hline Source of information on Pap smear & 231 & 66.4 \\
Lectures during undergraduate training & 89 & 25.6 \\
Colleagues/co-workers & 55 & 15.8 \\
Seminars/workshops & 15 & 4.3 \\
Mass media & 3 & 0.9 \\
Friends/family members & & \\
What is a Pap smear used for? & 268 & 77.0 \\
Screening for cervical cancer & 19 & 5.5 \\
Treatment of cervical cancer & 42 & 12.1 \\
Both screening and treatment of cervical cancer & 14 & 4.0 \\
Detection of HPV and other STIs & 5 & 1.4 \\
I do not know & & \\
Who should have a Pap smear done? & 105 & 30.2 \\
All sexually active women from 25 to 65 years of age & 102 & 29.3 \\
Only women of childbearing age & 96 & 27.6 \\
All sexually active women, irrespective of age & 24 & 6.9 \\
Only women with symptoms of cervical cancer & 8 & 2.3 \\
Only women with multiple sexual partners & 7 & 2.0 \\
I do not know & 6 & 1.7 \\
Women above 65 years & & \\
\hline
\end{tabular}

Association between sociodemographic characteristics and uptake of Pap smear

There was a significant association between age and Pap smear uptake, as FHPs aged 30 years and above were significantly more likely to have done a Pap smear than those less than 30 years $(25.0 \%$ vs $14.2 \% ; \mathrm{p}=0.024)$. More married/divorced/widowed women than single women had done a Pap smear $(22.4 \%$ vs. $15.5 \%$; $\mathrm{p}=0.197)$; so also, para 3 and above women compared to para $0-2(28.3 \%$ vs. $13.2 \%$; $=0.055)$. More physiotherapists and medical social workers reported having done a Pap smear compared to nurses, medical doctors, pharmacists and medical laboratory scientists ( $25 \%$ vs $25 \%$ vs $23.4 \%$ vs $16.4 \%$ vs $8.7 \%$ vs $5.3 \%$ respectively; $\mathrm{p}=0.327$ ). However, the associations between marital status, parity, and designation, and uptake of Pap smear were not statistically significant, as depicted in Table IV.

\section{Discussion}

The knowledge of CC and its risk factors and the detection of premalignant cervical lesions via screening are crucial to the prevention and elimination of CC. [20] This study showed very high levels of awareness of both CC and Pap smear amongst the FHPs. Other authors have corroborated this. [16, 20,21] This finding is not unexpected, as the FHPs would have acquired this knowledge during their training, ${ }^{[21]}$ as observed in the present study. 
Table IIIb: Knowledge and uptake of Pap smear amongst FHPs

\begin{tabular}{|c|c|c|}
\hline Characteristics & $\begin{array}{l}\text { Frequency } \\
n=348\end{array}$ & Percentage (\%) \\
\hline \multicolumn{3}{|l|}{ What is the frequency of Pap smear? } \\
\hline Every three years & 180 & 51.7 \\
\hline Every year & 91 & 26.1 \\
\hline Every five years & 61 & 17.5 \\
\hline Once in a lifetime & 11 & 3.2 \\
\hline I do not know & 5 & 1.4 \\
\hline \multicolumn{3}{|l|}{ What does a positive Pap smear result mean? } \\
\hline Abnormal cervical cells but not cervical cancer & 284 & 81.6 \\
\hline Cervical cancer & 47 & 13.5 \\
\hline STI & 12 & 3.4 \\
\hline I do not know & 5 & 1.4 \\
\hline \multicolumn{3}{|l|}{ Reason for not having done a Pap smear $(n=277)$} \\
\hline No reason & 109 & 31.3 \\
\hline I have not been able to take time off work to go for the test & 83 & 23.9 \\
\hline I believe I am not at risk of cervical cancer & 59 & 17.0 \\
\hline I think it is painful, and I am afraid of experiencing pain & 48 & 13.8 \\
\hline I am afraid of a positive result & 43 & 12.4 \\
\hline Cost of the test & 39 & 11.2 \\
\hline It is against my culture/religion & 15 & 4.3 \\
\hline Not aware of the availability of the service & 12 & 3.4 \\
\hline
\end{tabular}

The Pap smear awareness of $98.6 \%$ reported in this study is a significant improvement from the $69.8 \%$ reported by Aboyeji et al. in a previous study in the same institution 16 years ago. ${ }^{[15]}$ The increased level of awareness may not be unconnected with the improved consciousness of CC screening among the general population. [22] It is noteworthy that even though an overwhelming majority of our study respondents were aware of Pap smear, more than a fifth of them did not know what it is used for; only less than a third knew when it should be commenced. Almost one-half did not know the interval of screening. This calls for more training, education, and enlightenment of healthcare providers on CC screening. ${ }^{[22]}$ It should not be assumed that FHPs are sufficiently knowledgeable about Pap smear. ${ }^{[21]}$ With better knowledge, FHPs would be in a better position to recommend Pap smear to other women. ${ }^{[14]}$ This study findings confirmed this fact, as more doctors and nurses, who are expectedly more knowledgeable about CC, had recommended Pap smear to other women, compared to other FHPs.

The FHPs in this study also demonstrated good knowledge of the risk factors for CC. This is reassuring, especially because CC peaks in the fourth decade of life, [23] and nearly a third of the FHPs in the study fell within this age range. The majority were also multiparous and sexually active (married), which are known risk factors for CC. However, despite the high level of awareness 
and knowledge of CC and its risk factors, with a significant number of the FHPs in this study being at risk, only a fifth of them had ever done a Pap smear.

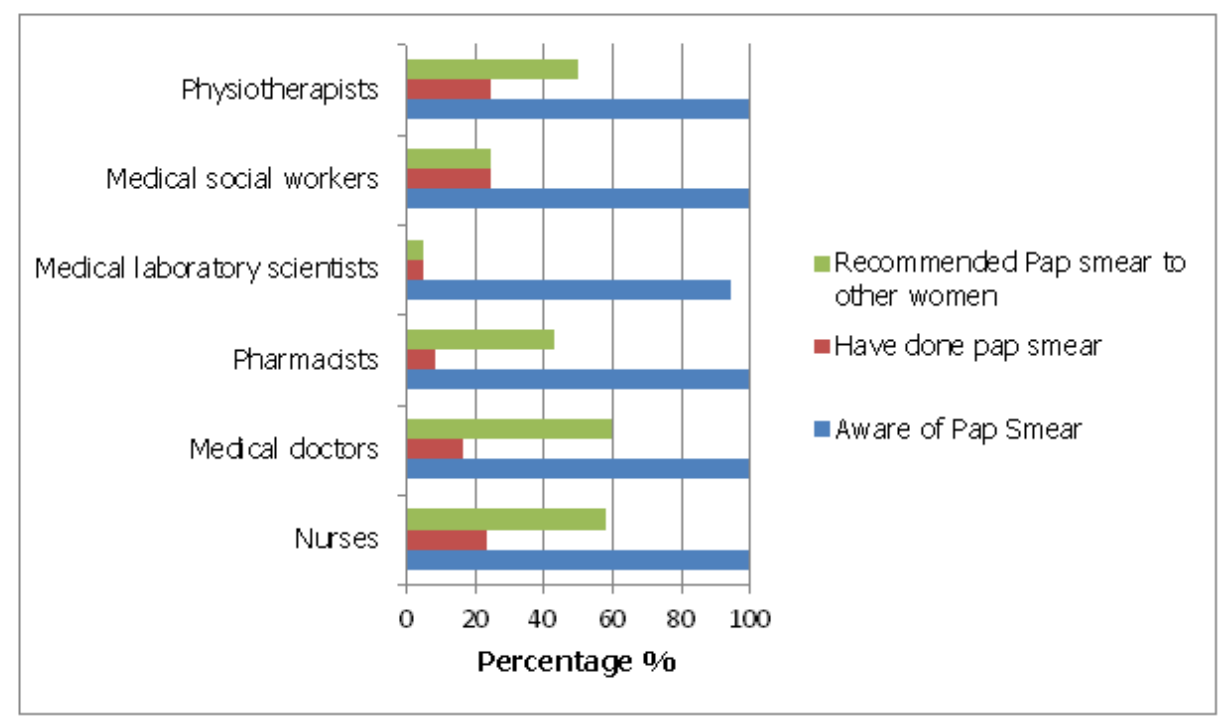

Figure 1: Awareness versus uptake of Pap smear by different cadres of FHPs in UITH

Therefore, the high awareness of Pap smear did not translate to increased uptake of the same. Even though the Pap smear uptake rate of 20.4\% in this study reflects a significant improvement from the $3 \%$ reported by Aboyeji et al. in a previous study, [15] it is still abysmal for FHPs, who should be at the forefront of CC screening programmes, and lead by example by subjecting themselves to the test. The low uptake of Pap smear in the present study corroborates other previous studies across the country. [22-24]

The most common reason reported by our study respondents for not having done a Pap smear was lack of time while at work to go for the test. This may not be unconnected with Nigerian healthcare personnel's long, unregulated work hours. This has been aggravated by the massive emigration of health workers, worsening the already poor doctor-to-patient ratio and the nurse-to-patient ratio of 4:10,000 and 15:10,000, respectively, [25,26] with the attendant consequence of long queues and prolonged waiting times in clinics and outpatient departments. In this study, more of the FHPs who had shorter working hours (physiotherapists and medical social workers) had done a Pap smear than those who worked longer hours (nurses, medical doctors, pharmacists, and medical laboratory scientists). Hospital-based periodic medicals (including Pap smear) for all healthcare workers would afford all hospital staff cadres the opportunity to be screened, irrespective of work schedules. Healthcare workers must also be reminded to find time to prioritise their health.

A fifth of the respondents in this study reported that they had not done a Pap smear because they believed they were not at risk for CC. Given the preponderance of young and single women in the study, this belief may not be unconnected with the misconception that CC affects older, married, and parous women, as reported by other authors. $[15,16,20]$ Oche et al. observed that $77.7 \%$ of female health workers in Sokoto intended doing a Pap smear when they are older and at greater risk, 
while Attah et al. revealed in their study in Jos that $10.3 \%$ of their study subjects preferred to be screened after marriage. [16,20] These misconceptions were also portrayed by the respondents in the present study, as significantly higher rates of uptake of Pap smear were observed in those aged 30 years and above, married, and with high parity. More so, $29 \%$ of the respondents in the present study believed that only childbearing women should do a Pap smear. There is a need to educate the populace that all sexually active women, irrespective of age, parity or marital status, are at risk of CC. [3,15]

Table IV: Association between sociodemographic characteristics, knowledge of cervical cancer and Pap smear and uptake of Pap smear

\begin{tabular}{|c|c|c|c|c|c|}
\hline \multirow[t]{2}{*}{ Variables } & \multicolumn{2}{|c|}{ Ever done a Pap smear? } & \multirow[t]{2}{*}{ df } & \multirow[t]{2}{*}{$\mathrm{X}^{2}$} & \multirow[t]{2}{*}{ p-value } \\
\hline & Yes $(n=71)$ & No $(n=277)$ & & & \\
\hline \multicolumn{6}{|l|}{ Age (years) } \\
\hline$<30$ & $21(14.2 \%)$ & $127(85.8 \%)$ & 4 & 11.22 & 0.024 \\
\hline$\geq 30$ & $50(25.0 \%)$ & $150(75.0 \%)$ & & & \\
\hline \multicolumn{6}{|l|}{ Marital status } \\
\hline Single & $16(15.5 \%)$ & $87(84.5 \%$ & 3 & 4.67 & 0.197 \\
\hline Married/divorced/widowed & $55(22.4 \%)$ & $190(77.6 \%)$ & & & \\
\hline \multicolumn{6}{|l|}{ Parity } \\
\hline $0-2$ & $24(13.2 \%)$ & $158(86.8 \%)$ & 3 & 5.80 & 0.055 \\
\hline$\geq 3$ & $47(28.3 \%)$ & $119(71.7 \%)$ & & & \\
\hline \multicolumn{6}{|l|}{ Designation } \\
\hline Nurse & $56(23.4 \%)$ & $183(76.6 \%)$ & & 0.887 & 0.327 \\
\hline Medical doctor & $9(16.4 \%)$ & $46(83.6 \%)$ & & & \\
\hline Pharmacist & $2(8.7 \%)$ & $21(91.3 \%)$ & & & \\
\hline Medical laboratory scientist & $1(5.3 \%)$ & $18(94.7 \%)$ & & & \\
\hline Physiotherapist & $2(25.0 \%)$ & $6(75.0 \%)$ & & & \\
\hline Medical social worker & $1(25.0 \%)$ & $3(75.0 \%)$ & & & \\
\hline \multicolumn{6}{|l|}{ Knowledge of Pap smear } \\
\hline Yes & $71(20.7 \%)$ & $272(79.3 \%)$ & 1 & 1.300 & 0.254 \\
\hline No & $0(0.0 \%)$ & $5(100.0 \%)$ & & & \\
\hline \multicolumn{6}{|l|}{ Knowledge of cervical cancer } \\
\hline Yes & $71(22.6 \%)$ & $243(77.4 \%)$ & 1 & 1.731 & 0.188 \\
\hline No & $0(0.0 \%)$ & $34(100.0 \%)$ & & & \\
\hline
\end{tabular}

Eleven per cent of the FHPs in the present study cited cost as the barrier to their uptake of Pap smear. Currently, cervical cancer screening is not covered by the National Health Insurance Scheme (NHIS) in Nigeria. ${ }^{[6]}$ Considering that $70 \%$ of Nigerians live on less than $\$ 1$ per day, outof-pocket spending of between $\$ 2,500$ (\$6.08) and $\$ 10,000$ (\$24.32), which is the cost of a Pap smear (depending on location) in Nigeria, is a lot of money for very many Nigerians. ${ }^{[6,27]}$ Extending NHIS coverage to include CC screening services would increase its uptake. It is also essential to educate the public that the cost of CC care is a lot more expensive than $\mathrm{CC}$ screening, which has the advantage of early detection when the possibility of a cure exists. [15]

Twelve per cent of the FHPs in the present study had not done a Pap smear because they were afraid of a positive result. This $12 \%$ may not be different from the $13 \%$ who thought a positive Pap smear meant CC. This misinformation needs to be corrected via public enlightenment and education. In addition, cultural and religious 
beliefs, and the misconception that Pap smear is a painful procedure, as volunteered by $4 \%$ and $14 \%$ of the respondents in this study, respectively, are also important considerations. Twelve FHPs in this study were not aware that Pap smear service was available in UITH. This is similar to findings in Ibadan and two referral hospitals in southeast Nigeria. [21,23] There is a need to increase publicity on the location of centres where Pap smear services exist across the country.

The poor uptake of Pap smear by the FHPs in the present study is also reflected in their attitude towards recommending the test to other women/patients, as only $54 \%$ of them had ever recommended the test to others. Other studies have cited non-recommendation by a healthcare provider as a reason for non-/ poor uptake of Pap smear.[16,24] "Physician recommendation is one of the most powerful predictors of screening across all age, socioeconomic, and ethnic groups".,[28] Therefore, a consequence of the poor recommendation of CC screening services by healthcare providers, as seen in the present study, would be poor uptake of these services by the general population and an increase in incidence and mortality from CC.

\section{Conclusion}

This study has revealed that despite the high knowledge and awareness of CC and CC screening, attitude and uptake are poor, even amongst FHPs. There is a need for further training, education and enlightenment of healthcare personnel on the benefits of CC screening. This is to increase their uptake and improve their effectiveness in promoting positive attitudes towards CC prevention in the general population. Organised CC screening programmes would also go a long way in increasing uptake.
Authors' Contributions: OAO, SMM, OAO2, and AIF conceived and designed the study. SMM, UAE, NS, and OPC did the literature review. SMM and UAE analysed and interpreted the data. SMM, UAE, NS and OPC drafted the manuscript. IOA, AL and IJI revised the draft for sound intellectual content. All authors approved the final version of the manuscript.

Conflicts of Interest: None.

Funding: Self-funded.

Publication History: Submitted 06 November 2021, Accepted 28 November 2021.

\section{References}

1. Stewart TS, Moodley J, Walter FM. 2018. Population risk factors for late-stage presentation of cervical cancer in sub-Saharan Africa. Cancer Epidemiol 2018; 53: 81-92. https://doi.org/10.1016/j.canep.2018.01.014

2. Huang HY, Tsai WC, Chou WY, Hung YC, Liu LC, Huang KF et al. Quality of life of breast and cervical cancer survivors. BMC Women's Health 2017; 17: 1-2. https://doi.org/10.1186/s12905-017-0387-x

3. Asseffa NA. Cervical cancer: Ethiopia's outlook. J Gynecol Women's Health 2017; 5: 555660 .

http://dx.doi.org/10.19080/jgwh.2017.05.55 $\underline{5660}$

4. Adibe MO, Aluh DO. Awareness, knowledge and attitudes towards cervical cancer amongst HIV-positive women receiving care in a Tertiary Hospital in Nigeria. J Cancer Educ 2018; 33: 1189-1194. https://doi.org/10.1007/s13187-017-1229-0

5. Bisi-Onyemaechi AI, Chikani UN, Nduagubam O. Reducing incidence of cervical cancer: knowledge and attitudes of caregivers in Nigerian city to human papillomavirus vaccination. Infect Agent Cancer 2018; 13: 1-6. https://doi.org/10.1186/s13027-018-0202-9 
6. Ilevbare OE, Adegoke AA, Adelowo CM. Drivers of cervical cancer screening uptake in Ibadan, Nigeria. Heliyon 2020; 6: e03505. https://doi.org/10.1016/j.heliyon.2 $\underline{020 . e 03505}$

7. Olubodun T, Odukoya OO, Balogun MR. Knowledge, attitude and practice of cervical cancer prevention among women residing in an urban slum in Lagos, Southwest Nigeria. Pan Afr Med J 2019; 32: 130. https://dx.doi.org/10.11604\%2Fpamj.2019.3 2.130 .14432

8. Sowemimo OO, Ojo OO, Fasubaa OB. Cervical cancer screening and practice in low resource countries: Nigeria as a case study. Trop J Obstet Gynaecol 2017; 34: 170-6. https://doi.org/10.4103/TJOG.TJOG_66_17

9. Mahmoodi P, Fani M, Rezayi M, Avan A, Pasdar Z, Karimi E et al. Early detection of cervical cancer based on high-risk HPV DNAbased genosensors: A systematic review. Biofactors 2019; 45: 101-117. https://doi.org/10.1002/biof.1465

10. Aral SO, Holmes KK. The epidemiology of STIs and their social and behavioural determinants: industrialised and developing countries. In: Holmes KK, Sparling PF, Stamm WE, Piot P, Wasserheit JN, Corey L, et al. (Editors). Sexually Transmitted Diseases. 4th Edition. New York: McGraw-Hill; 2008: p. 53-92.

11. Bruni L, Diaz M, Castellsagué M, Ferrer E, Bosch FX, de Sanjosé S. Cervical human papillomavirus prevalence in 5 continents: meta-analysis of 1 million women with normal cytological findings. J Infect Dis 2010; 202:

1789-1799.

https://doi.org/10.1086/657321

12. Graham JE, Mishra A. Global challenges of implementing human papillomavirus vaccines. Int J of Equity Health 2011; 10: 1. https:// doi.org/10.1186/1475-9276-10-27
13. Okonofua F. HPV vaccine and prevention of cervical cancer in Africa. Afr J Reprod Health 2007; 11: 7-12. https://hdl.handle.net/10520/EJC122003

14. Ugwu EO, Obi SN, Ezechukwu PC, Okafor II, Ugwu AO. Acceptability of human papillomavirus vaccine and cervical cancer screening among female healthcare workers in Enugu, Southeast Nigeria. Niger J Clin Pract 2013; 16: 249-252. https://doi.org/10.4103/1119-3077.110141

15. Aboyeji PA, Ijaiya MA, Jimoh AA. Knowledge, attitude and practice of cervical smear as a screening procedure for cervical cancer in Ilorin, Nigeria. Trop J Obstet Gynaecol 2004; 21: 114-117. https:// doi.org/10.4314/tjog.v21i2.14482

16. Attah D, Ochejele S, Attah M, Ochoga M. Comparison of Knowledge, Attitude and Acceptance of Cervical Cancer Screening Between Female Health and Non-Health Personnel in Jos University Teaching Hospital. J BioMed Res Clin Pract 2019; 2: 113120. https:// doi.org/10.46912/jbrcp.118

17. Akokuwebe ME, Idemudia ES, Lekulo AM, Motlogeloa OW. Determinants and levels of cervical cancer screening uptake among women of reproductive age in South Africa: evidence from South Africa Demographic and health survey data, 2016. BMC Public Health 2021;21(1):1-4. https://doi.org/10.1186/s12889-021-12020-z

18. Udigwe GO. Knowledge, attitude and practice of cervical cancer screening (Pap smear) among female nurses in Nnewi, Southeastern Nigeria. Niger J Clin Pract 2006; 9: 40-43.

19. Akinola OI, Aimakhu CO, Ezechi OC, Fasubaa OB. Society of Obstetrics and Gynaecology of Nigeria- Clinical practice guidelines: Guidelines for the prevention of cervical cancer. Trop J Obstet Gynaecol 2018; 35:

371-376.

https://doi.org/10.4103/TJOG.TJOG_88_18 
20. Oche MO, Kaoje AU, Gana G, Ango JT. Cancer of the cervix and cervical screening: Current knowledge, attitude and practices of female health workers in Sokoto, Nigeria. Int J Med Med 2013; 5: 184-190. https:/ / doi.org/10.5897/IJMMS2013.0886

21. Anya SE, Oshi DC, Nwosu SO, Anya AE. Knowledge, attitude, and practice of female health professionals regarding cervical cancer and pap-smear. Niger J Med 2005; 14: 283-286.

22. Dim CC, Ekwe E, Madubuko T, Dim NR, Ezegwui HU. Improved awareness of Pap smear may not affect its use in Nigeria: a case study of female medical practitioners in Enugu, Southeastern Nigeria. Trans R Soc Trop Med Hyg 2009; 103: 852-854. https://doi.org/10.1016/j.trstmh.2009.03.02 $\underline{0}$

23. Ayinde OA, Omigbodun AO. Knowledge, attitude and practices related to prevention of cancer of the cervix among female health workers in Ibadan. J Obstet Gynaecol 2003; 23:

59-62. https://doi.org/10.1080/01443610210000432 $\underline{72}$

24. Bakari M, Takai IU, Bukar M. Awareness and utilisation of Papanicolaou smear among health care workers in Maiduguri, Nigeria.
Niger J Basic Clin Sci 2015; 12: 34-38. https://doi.org/10.4103/0331-8540.156682

25. Ijarotimi OA, Ubom AE, Olofinbiyi BA, KuyeKuku T, Orji EO, Ikimalo JI. COVID-19 and obstetric practice: A critical review of the Nigerian situation. Int J Gynecol Obstet 2020; 151:

17-22.

https://doi.org/10.1002/ijgo.13325

26. Ubom AE, Adesunkanmi AO, Ndegbu CU, Balogun SA, Ajekwu SC, Sowemimo SO et al. Nigerian Surgical Trainees' Work Schedule: It is Time for a Change!. World J Surg 2021; 45: 2653-2660. https://doi.org/10.1007/s00268$\underline{021-06182-5}$

27. Adesunkanmi AO, Ubom AE, Olasehinde O, Fasubaa OB, Ijarotimi OA, Adesunkanmi ARK et al. Impact of COVID-19 on the cost of surgical and obstetric care: experience from a Nigerian teaching hospital and a review of the Nigerian situation. Pan Afr Med J 2020; 37: 15.

https://dx.doi.org/10.11604\%2Fpamj.supp.2 $\underline{020.37 .1 .25935}$

28. Mandelblatt JS, Yabroff KR. Breast and cervical cancer screening for older women: recommendations and challenges for the 21st century. J Am Med Womens Assoc 2000; 55: 210-215. 